\title{
Optimization of Hydraulic Oil Seal in Earth Movers
}

\author{
R. Vishnu Ramesh Kumar ${ }^{1}$, V. Varun Sagar $^{2}$, P. Vishnuram ${ }^{3}$, N. Hari Prasanth ${ }^{4}$ \\ ${ }^{1}$ Assistant Professor, Department of Automobile Engineering, Dr. Mahalingam College of Engineering and Technology, Pollachi-642003 \\ Affiliated to Anna University: 600025 \\ ${ }^{2,3,4}$ Undergraduate Student, Department of Automobile Engineering, Dr. Mahalingam College of Engineering and Technology, Pollachi- \\ 642003 Affiliated to Anna University: 600025
}

\begin{abstract}
This project aims at increasing the durability of the oil seal used in earth movers considering the design and material of the oil seal being unchanged. We increase the heat dissipation of the oil seal by providing coating on the frontal surface of the oil seal thus enhancing the heat flow from the oil seal to the environment. The enhanced heat transfer in the oil seal enables earth movers to work for longer duration at elevated temperatures. From the availability of more materials/powders like super alloy powders, power blend powders, thermal spray powders, chemical clad powders, aluminium, nickel, chromium, molybdenum, titanium, vanadium, tungsten etc., for coating the oil seal, the aluminium is being selected with respect to the availability, cost and also its heat dissipation capacity to the oil seal. Thus with the increase in the heat dissipation of the oil seal, the durability also increases with respect to it. The oil seal is examined for the improvement in heat dissipation and since the corrosion determines the life of the aluminium coating on the oil seal, we examine for the corrosive resistance.
\end{abstract}

Keywords: NBR, Aluminium, Corrosion Resistance, Heat Resistance, Heat Soak

\section{Introduction}

The project was mainly based on the survey reports taken on the earth movers and defense related vehicles, where we found that the hydraulic power lines in these vehicles have some common problem. The oil seal that is being used in the hydraulic cylinders has been failed after 500 hours of its usage in the cylinder because of the less heat resistance of the oil seal. To fix that this was only the unique problem in these power lines, we took survey with 12 operators in and around our home city. From the survey reports we found the durability of the oil seal is being reduced due its low thermal convection.

The aim of this thesis is to optimise the hydraulic seal of the earth movers i.e., to increase its heat convection from system to environment, thus resulting in the enhanced heat dissipation which increases the durability of the oil seal.

\section{Methodology}

Elastomeric seals play an important role in the field of modern industry, which are the key to guarantee the reliable performance of mechanical systems ${ }^{[2]}$. They are widely applied in various environments of hydraulic systems, especially for static and dynamic seals with rubber sealing materials. However, leakage is a serious potential problem in hydraulic systems. As one of the most important indexes to evaluate the sealing performance, leakage depends on many factors, such as the seal material, operating temperature, driving pressure, seal compression and seal geometry ${ }^{[5]}$. Therefore, effects of these factors on the behaviour of the seal should be thoroughly understood and the leakage rate is reasonably determined, which is the primary mission of the seal design. Thus the various temperature limits of the existing oil seal materials are shown in table 1.

The existing material of commercial oil seals are;
- HNB(Highly Saturated Rubber)

- TFV(Virgin PTFE)

- SIL(Silicone Rubber)

Table 1: Temperature limits of Existing Materials

\begin{tabular}{|c|c|}
\hline Material & Temperature Limits \\
\hline NBR & -30 to $100^{\circ} \mathrm{C}$ \\
\hline HNB & -25 to $150^{\circ} \mathrm{C}$ \\
\hline SIL & -60 to $200^{\circ} \mathrm{C}$ \\
\hline TFV & -200 to $260^{\circ} \mathrm{C}$ \\
\hline
\end{tabular}

Our inference from the survey is that the durability of the oil seal is low due to insufficient thermal capacity of the material. Our ideology is to provide coating on the frontal surface of the oil seal. Thus the additional coating helps in the enhanced dissipation of heat thus resulting increased refractory index. For the enhanced heat dissipation we use the material that has high refractory index so the part of the seal material is changed.

This approach enables us to increase the durability of the oil seal without making changes in the existing material and design, thus this approach doesn't affect the cost and time at the major level. This approach just requires the addition of coating process. The material to be coated is selected based upon the high temperature coefficient, high formability, and anticorrosive in nature. The properties of aluminium is shown in table 2 .

Table 2: Properties of Aluminium

\begin{tabular}{|c|c|}
\hline Parameters & Properties \\
\hline Yield Strength & $40 \mathrm{ksi}$ \\
\hline Hardness & 95 Brinell \\
\hline Melting Point & 1080 to $1250 \mathrm{~F}$ \\
\hline Pressure & 15 PSI \\
\hline
\end{tabular}

The coating material is chosen based upon the availability, affordability, durability enhancing properties considering the manufacturing process and cost.

- NBR(Nitrile Butadiene Rubber) 


\section{International Journal of Science and Research (IJSR) \\ ISSN (Online): 2319-7064 \\ Index Copernicus Value (2013): 6.14 | Impact Factor (2014): 5.611}

We have wide variety in aluminium alloys which are applicable for coating in the NBR oil seal. The Physical and
Mechanical properties of aluminium alloys are studied and listed in table 3 .

Table 3: Comparison Chart of Properties of Aluminium Alloys

\begin{tabular}{|c|c|c|c|c|c|c|c|}
\hline Parameters & A356 & $A 360$ & $A 380$ & ADC12 & LM2 & LM5 & LM24 \\
\hline Density $\left(\mathrm{g} / \mathrm{cm}^{\wedge}\right.$ 3) & 2.67 & 2.68 & 2.76 & 2.82 & 2.74 & 2.65 & 2.79 \\
\hline Heat Capacity (J/g-K) & 0.963 & 0.963 & 0.963 & 0.963 & 0.963 & 0.963 & 0.963 \\
\hline Thermal Conductivity (W/mK) & 151 & 113 & 109 & 92 & 100 & 138 & 963 \\
\hline Melting Range ('C) & $557-613$ & $557-596$ & $538-593$ & $516-582$ & $525-570$ & $580-642$ & $520-580$ \\
\hline Tensile Strength, Ultimate (MPa) & 234 & 317 & 324 & 331 & 300 & $170-280$ & 320 \\
\hline Tensile Strength, Yield (MPa) & 165 & 165 & 159 & 165 & 130 & $90-120$ & 150 \\
\hline Elongation (\%) & 3.5 & 3.5 & 3.5 & 2.5 & $1-3$ & 5 & $1-3$ \\
\hline
\end{tabular}

From the comparison, A360 is best suited for good thermal conductivity and high corrosion resistance. Hence we choose A360 as the coating material for the oil seal. The corrosive resistance is important factor to be considered because the earth movers working environment may be highly humid in nature.

\subsection{Design}

\subsubsection{Modelling}

The oil seal that we work in are modelled by the various software's that are being user-friendly in using the commands and also the every feature.

The modelling of the oil seal \& piston cylinder arrangements is very easy and also the softwares used for modelling are;

1) CREO (PRO-E)

2) SOLID WORKS 2013

The model of the hydraulic cylinder assembly is given below which is taken from Solid Works 2013. The piston cylinder arrangement and the various parts of the piston cylinder arrangement is shown in figures 1 to 4 .

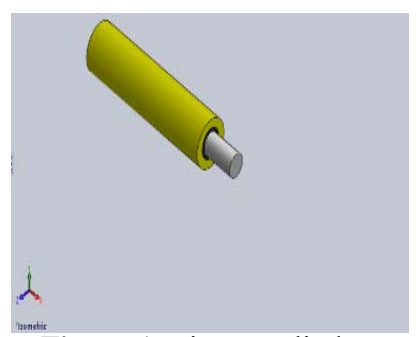

Figure 1: Piston Cylinder Arrangement

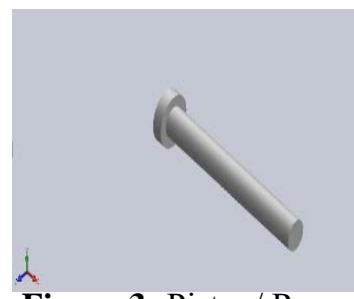

Figure 3: Piston/ Ram

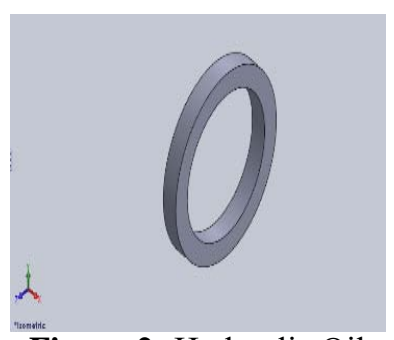

Figure 2: Hydraulic Oil Seal

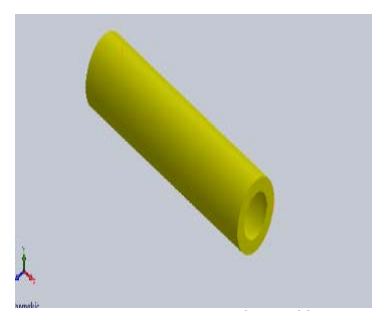

Figure 4:Hydraulic Cylinder

\subsubsection{Dimensions}

The dimensions of the oil seal are provided in the figure 5 and table 4.

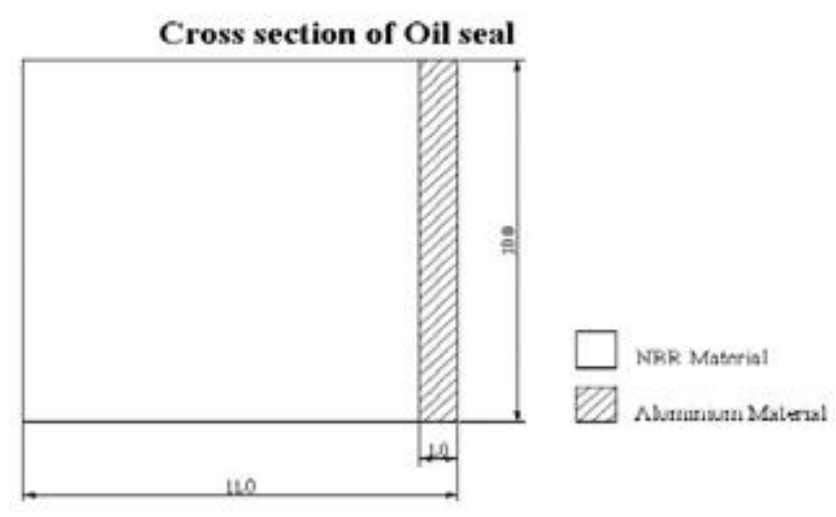

ALI DAMETSIONS NIS IN HaH

Figure 5: Cross Sectional Dimension of oil seal

Table 4: Dimensions of coated oil seal

\begin{tabular}{|c|c|}
\hline Parameters & Dimensions \\
\hline Outer Diameter & $65 \mathrm{~mm}$ \\
\hline Inner Diameter & $45 \mathrm{~mm}$ \\
\hline Width & $11 \mathrm{~mm}$ \\
\hline
\end{tabular}

\subsection{Coating}

Coatings have historically been developed to provide protection against corrosion and erosion that is to protect the material from chemical and physical interaction with its environment. Corrosion and wear problems are still of great relevance in a wide range of industrial applications and products as they result in the degradation and eventual failure of components and systems both in the processing and manufacturing industries and in the service life of many components.

Technologies in various numbers are used to deposit the appropriate surface protection that can resist under specific conditions. They are usually distinguished by coating thickness: deposition of thin films (below 10 to $20 \mu \mathrm{m}$ according to authors) and deposition of thick films. The latter, mostly produced at atmospheric pressure have a thickness over $30 \mu \mathrm{m}$, up to several millimeters and are used when the functional performance and life of component depend on the protective layer thickness. Both coating technology can also be divided into two distinct categories: wet and dry coating methods, the crucial difference being the medium in which the deposited material is processed.

The former group mainly involves electroplating, electro less plating and hot-dip galvanizing while the second includes, among others methods, vapor deposition, thermal spray 


\section{International Journal of Science and Research (IJSR) \\ ISSN (Online): 2319-7064}

Index Copernicus Value (2013): 6.14 | Impact Factor (2014): 5.611

techniques, brazing, or weld overlays. It is defined by Hermanek (2001) as follows, "Thermal spraying comprises a group of coating processes in which finely divided metallic or non-metallic materials are deposited in a molten or semimolten condition to form a coating". The coated oil seal shown in the figure 6.

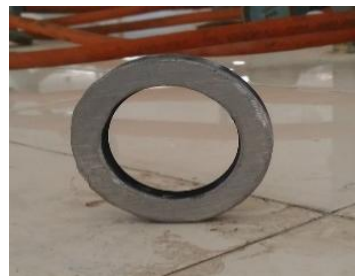

Figure 6: Oil Seal

The processes comprise: direct current (D.C) arcs or radio frequency (R.F) discharges-generated plasmas, plasma transferred arcs (PTA), wire arcs, flames, high velocity oxyfuel flames (HVOF), high velocity air-fuel flames (HVAF), detonation guns (D-gun). Another spray technology has emerged recently; it is called cold gas-dynamic spray technology, or Cold Spray (CS). It is not really a thermal spray technology as the high energy gas flow is produced by a compressed relatively cold gas $\left(\mathrm{T}<800^{\circ} \mathrm{C}\right)$ expanding in a nozzle and will not be included in this presentation.

Thermal spray is a generic term for a group of processes in which metallic, ceramic, cermet, and some polymeric materials in the form of powder, wire, or rod are fed to a torch or gun with which they are heated to near or somewhat above their melting point. The resulting molten or nearly molten droplets of material are accelerated in a gas stream and projected against the surface to be coated (i.e., the substrate). On impact, the droplets flow into thin lamellar particles adhering to the surface, overlapping and interlocking as they solidify. The total coating thickness is usually generated in multiple passes of the coating device.

\subsection{Heat Soak Prediction}

Heat soak prediction is highly applicable for pump/ seal systems and this prediction is very effective compared to the detailed computations of Computational Fluid Dynamics (CFD), Finite Element Analysis (FEA) or even the fin analogy ${ }^{[10]}$.

Sufficiently accurate heat soak estimates can be obtained by making slight modifications to the API 682 heat soak equation $^{[10]}$,

$Q=k \Delta T t$

$h=\frac{Q}{A_{f}}$

$U=\sqrt{\left(\frac{h k}{L}\right)\left(\frac{t}{L}\right)}$

$H_{s}=m_{1} m_{2} m_{3} m_{4} m_{5} m_{6} U A_{f} \Delta T$

Where,

$\mathrm{H}_{\mathrm{s}}=$ Heat Soak

$\mathrm{m}_{1}=$ Speed Factor

$\mathrm{m}_{2}=$ Thermal Conductivity Factor

$\mathrm{m}_{3}=$ Thickness Factor

$\mathrm{m}_{4}=$ Bore Factor $\mathrm{m}_{5}=$ Viscosity Factor

$\mathrm{m}_{6}=$ Combined Fluid Properties factor excluding

viscosity

$\mathrm{U}=$ The API default of $12 \mathrm{~S}$ ( $\mathrm{S}$ is the seal size)

$\mathrm{A}_{\mathrm{f}}=$ Convection area

$\Delta T=$ Seal to liquid temperature

$\mathrm{h}=$ Convective heat transfer coefficient

$\mathrm{t}=$ Wall thickness

$\mathrm{L}=$ Width of the oil seal

$\mathrm{k}=$ Thermal conductivity

$\mathrm{Q}=$ Rate of heat transfer

\subsection{Corrosion Rate Prediction:}

Corrosion can be defined as the gradual destruction of a metal by an unwanted chemical or electrochemical attack by its environment starting at the surface. The rate of corrosion depends upon two major factors namely, the nature of the metal and the environmental surrounding of the metal.

The weight loss is widely employed to measure the rate of corrosion. This method is simple, direct and versatile as we get direct measurement about corrosion rate without use of sophisticated instruments in all corrosive environments. In this method a clean weighed specimen of the metal or alloy is exposed to the corrosive environment for a suitable time. The specimen is then cleaned for removing all the corrosion products and then is reweighed. The loss in weight is noted. The rate of the metal removal due to the corrosion is then calculated.

\subsubsection{Corrosion Test}

Test specimen of aluminium coated oil seal to be tested is measured to determine dimensions, cleaned to remove grease and oxidation films, rinsed in distilled water and dried. Specimen is weighed and immersed in a test solution in glass jar with screw caps and placed in an incubator at the test temperature, undisturbed for 2 hours. The specimen is rinsed to remove residual test solution and loose corrosion products, cleaned with the appropriate solution and dried. Specimenis weighed and the change in weight during immersion is used to determine the corrosion rate ${ }^{[9]}$.

\subsubsection{Preparation of Test Solution:}

Test solution should be prepared usually 30 minutes before use. The salt solution of $250 \mathrm{ml}$ is prepared with $5 \% \mathrm{NaCl}$. The composition of sodium chloride crystals used is illustrated in table 5 and test solution in figure 7.

Table 5: Composition of Sodium Chloride

\begin{tabular}{|c|c|}
\hline \multicolumn{2}{|c|}{ Sodium Chloride } \\
\hline \multicolumn{2}{|c|}{ Molar Concentration $=58.44 \mathrm{~g} / \mathrm{mol}$} \\
\hline Assay $(\mathrm{NaCl})$ & $99 \%$ \\
\hline Sulphate $\left(\mathrm{SO}_{4}\right)$ & $0.02 \%$ \\
\hline Phosphate $\left(\mathrm{PO}_{4}\right)$ & $0.005 \%$ \\
\hline Nitrogen $(\mathrm{N})$ & $0.001 \%$ \\
\hline Heavy Metals $(\mathrm{as} \mathrm{Pb})$ & $0.0005 \%$ \\
\hline Iron $(\mathrm{Fe})$ & $0.001 \%$ \\
\hline Calcium $(\mathrm{Ca})$ & $0.002 \%$ \\
\hline
\end{tabular}




\section{International Journal of Science and Research (IJSR) \\ ISSN (Online): 2319-7064}

Index Copernicus Value (2013): 6.14 | Impact Factor (2014): 5.611

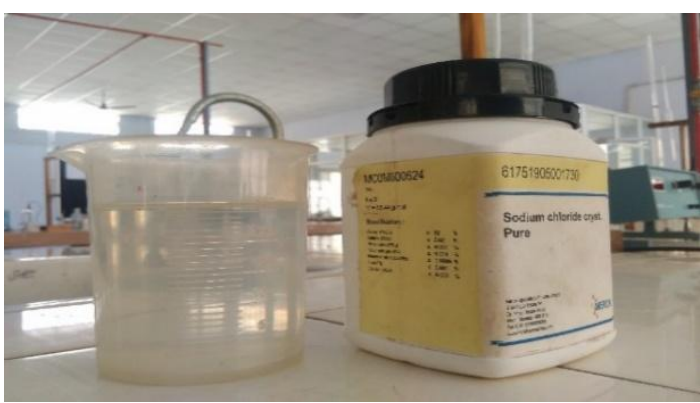

Figure 7: Test Solution

\subsubsection{Preparation of Specimen:}

Specimen is an aluminium coated oil seal of dimension refer table 4 . Oil seal is nominally $7 \mathrm{~mm}$ in width and $22.5 \mathrm{~mm}$ in diameter, aluminium coated with thickness of $1 \mathrm{~mm}$ at outer end of the oil seal. In the laboratory, specimen is marked for the purpose of identification and differentiation from others. Each coupon is then measured, to the nearest $0.001 \mathrm{~cm}$, in each of the 3 dimensions. The width and thickness are measured randomly on the surface of the aluminium.

\subsubsection{Specimen Immersion}

The jars are partially filled with test solution. Then the specimen is immersed in the jar containing the test solution. The jars are then placed into preheated incubators at the proper temperature, $70{ }^{\circ} \mathrm{F}$ or $120^{\circ} \mathrm{F}\left(21{ }^{\circ} \mathrm{C}\right.$ or $\left.49{ }^{\circ} \mathrm{C}\right)$, and left undisturbed during the 2 hours -day exposure period. See figure 8.

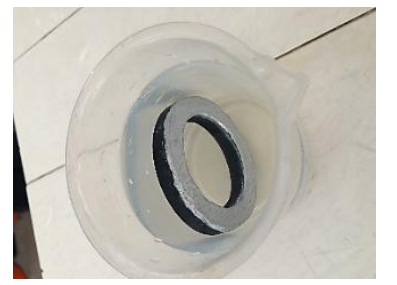

Figure 8: Specimen Immersion

\subsubsection{Corrosion Rate}

The corrosion rate is calculated for each coupon using the initial and final weights, control weight loss, coupon surface area, and density of the alloy and exposure time in the formula.

Corrosion Rate, $C_{r}=\frac{534\left(w t_{i}-w t_{F}\right)}{A t d}$

Where,

$$
\begin{aligned}
& \mathrm{Wt}_{\mathrm{i}}=\text { Specimen initial weight, } \mathrm{mg} \\
& \mathrm{Wt}_{\mathrm{F}}=\text { Specimen final weight, } \mathrm{mg} \\
& \mathrm{A}=\text { surface area of the specimen, } \mathrm{in}^{2} \\
& \mathrm{t}=\text { exposure time, hrs. } \\
& \mathrm{d}=\text { density of the alloy, } \mathrm{g} / \mathrm{cm}^{3}
\end{aligned}
$$

\section{Results and Discussion}

\subsection{Meshing}

The meshing of the piston cylinder arrangement is done using HYPERMESH 13.0 and the pre-processing is being continued in the ANSYS Workbench for the force convergence using Newton Raphson Method for defining the contact pairs.
The figures $9 \& 10$ represents the meshed model for the piston cylinder arrangementand The figures 11 \& 12 represents the meshed model of the oil seal.

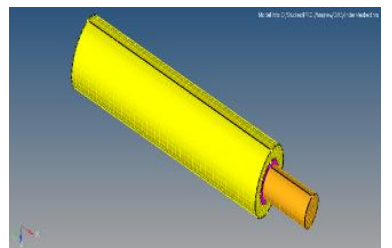

Figure 9: Piston Cylinder Arrangement

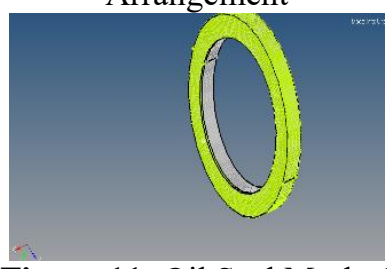

Figure 11: Oil Seal Meshed Model

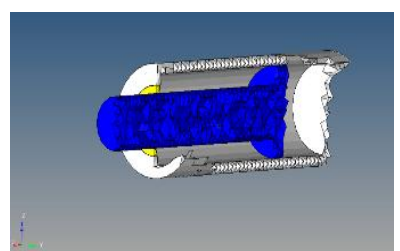

Figure 10: Cross Section of Piston Cylinder Arrangement

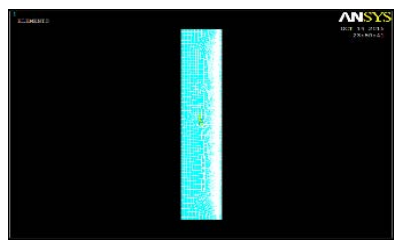

Figure 12: Oil seal Meshed Model- 2D View

\subsection{Force Convergence}

The force convergence is taken for the piston cylinder arrangement is taken for the contact pairs in the model using Newton Raphson Method for solving the contact pairs in ANSYS Workbench 14.0. Refer Figure $13 \& 14$

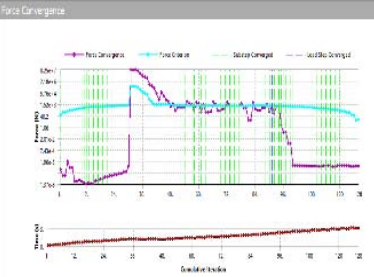

Figure 13: Force

Convergence for NBR without Coating

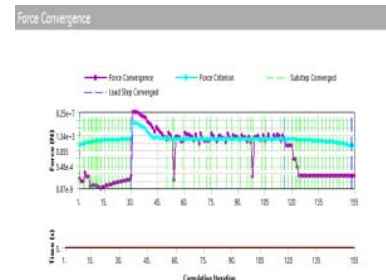

Figure 14: Force Convergence for NBR with Aluminium Coating

\subsection{Results}

The post processing was done in the ANSYS Mechanical APDL 14.0 and the results provided with respect to the graph plotted and is being inferred. Refer Figure: $15 \& 16$ 


\section{International Journal of Science and Research (IJSR) \\ ISSN (Online): 2319-7064}

Index Copernicus Value (2013): 6.14 | Impact Factor (2014): 5.611

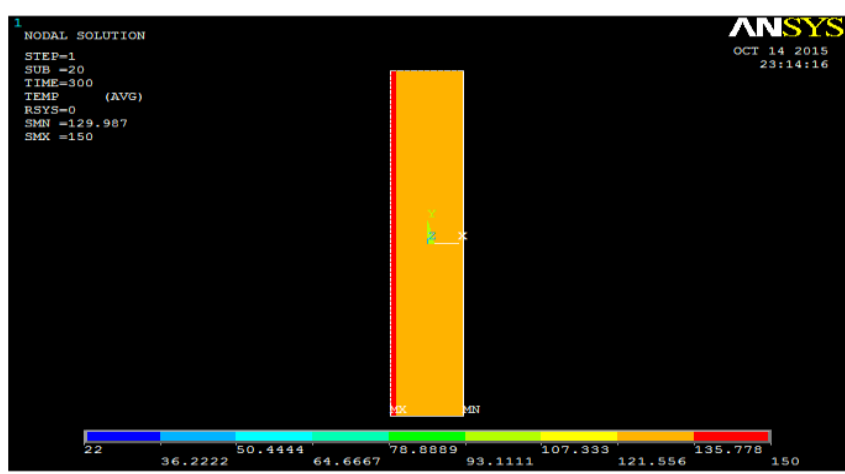

Figure 15: Heat dissipation in NBR Oil seal without Aluminium coating

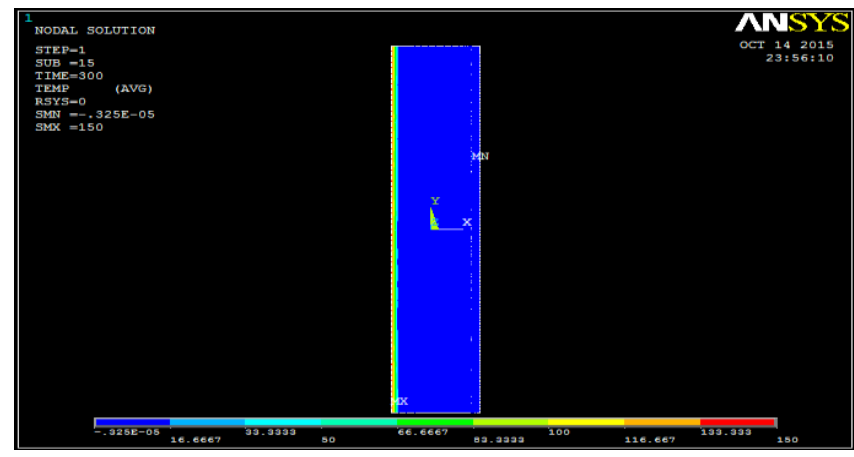

Figure 16: Heat dissipation in NBR Oil seal with Aluminium coating

\subsubsection{Graphical Method}

The graphs are plotted for the heat disspated in the oil seal with respect to time. Refer figure $17 \& 18$

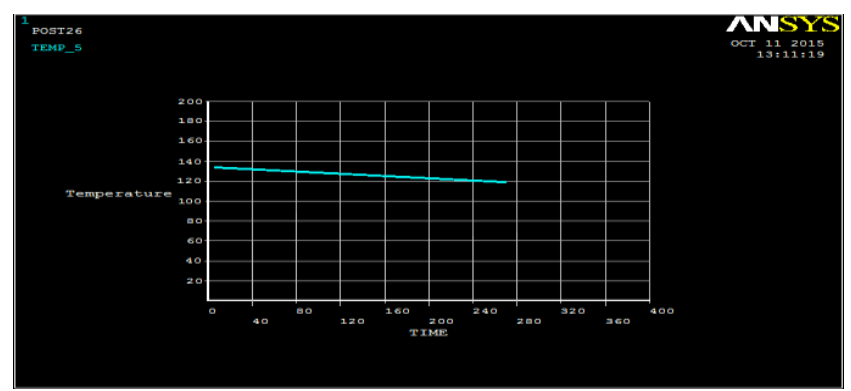

Figure 17: Heat dissipation in NBR Oil seal without Aluminium coating- Graph

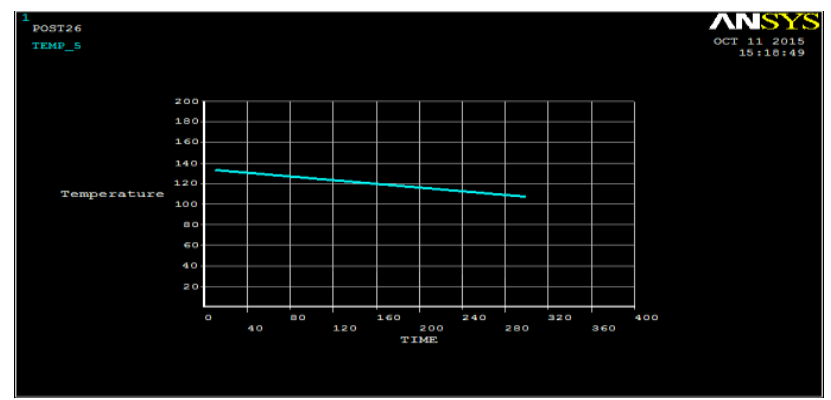

Figure 18: Heat dissipation in NBR Oil seal with Aluminium coating- Graph

\subsection{Heat Soak Calculation}

\subsubsection{NBR Calculation:}

Rate of Heat Transfer, $\mathbf{Q}=\mathbf{k} \Delta \mathbf{T t}$

(From 1)
Change in Temperature, $\Delta \mathrm{T}=120 \mathrm{~K}$

Thickness, $\mathbf{t}=0.01 \mathrm{~m}$

$$
\begin{gathered}
\mathrm{Q}=0.24 \times 120 \times 0.01 \\
\mathbf{Q}=\mathbf{0 . 2 8 8} \mathbf{W}
\end{gathered}
$$

Convective heat transfer coefficient, $h=\frac{\mathbf{Q}}{\mathbf{A}_{\mathbf{f}}}$ (From 2)

$\mathrm{Q}=0.288 \mathrm{~W}$

Convection Area, $A_{f}=\pi r^{2}$

$$
\begin{aligned}
\mathrm{A}_{\mathrm{f}} & =0.00172787 \mathrm{~m}^{2} \\
\mathrm{~h} & =\frac{0.288}{0.00172787} \\
\mathbf{h} & =\mathbf{1 6 6 . 6 7 9} \frac{W}{\boldsymbol{m}^{2}}
\end{aligned}
$$

The API default for 12S, $\mathbf{U}=\sqrt{\left(\frac{\mathrm{hk}}{\mathrm{L}}\right)\left(\frac{\mathrm{t}}{\mathrm{L}}\right)} \quad($ From 3)

Thickness, $\mathrm{t}=0.01 \mathrm{~m}$

Width of the oil seal, $\mathrm{L}=0.065 \mathrm{~m}$

$$
\begin{gathered}
U=\sqrt{\left(\frac{166.679 * 0.24}{0.065}\right)\left(\frac{0.01}{0.065}\right)} \\
U=\sqrt{94.6817} \\
\mathbf{U}=\mathbf{9 . 7 3}
\end{gathered}
$$

Heat Soak, $\mathbf{H}_{\mathbf{s}}=\mathbf{m}_{1} \mathbf{m}_{\mathbf{2}} \mathbf{m}_{3} \mathbf{m}_{\mathbf{4}} \mathbf{m}_{5} \mathbf{m}_{6} \mathbf{U} \mathbf{A}_{\mathbf{f}} \Delta \mathbf{T}($ From 4$)$

Speed factor, $\mathrm{m}_{1}=1$ (Since the fluid is constant)

Thermal Conductivity factor, $\mathrm{m}_{2}=1$ (According to API 682)

Thickness factor, $\mathrm{m}_{3}=1.13$ (For 1.5" grade seals, according to API 682)

Bore factor, $\mathrm{m}_{4}=1$ (According to API 610 standard bore and seal size)

Viscosity factor, $\mathrm{m}_{5}=1$ (Base case, according to API 682)

Combined fluid properties factor, $\mathrm{m}_{6}=0.78$ (Synthetic oil barrier fluids)

$$
\begin{aligned}
\mathrm{H}_{\mathrm{s}}=1 \times 1 \times 1.13 & \times 1 \times 1 \times 0.78 \times 9.73 \times 0.00172787 \\
\times & 120
\end{aligned}
$$

$$
H_{s}=1.77819 \mathrm{~J} / \mathrm{s}
$$

\subsubsection{Aluminium Calculation:}

Rate of Heat Transfer, $\mathbf{Q}=\mathbf{k} \Delta \mathrm{Tt}$ (From 1)

Thermal conductivity of Aluminium, $\mathrm{k}=205 \frac{\mathrm{W}}{\mathrm{mK}}$

Change in Temperature, $\Delta \mathrm{T}=120 \mathrm{~K}$

Thickness of aluminium, $\mathbf{t}=0.001 \mathrm{~m}$

$$
\begin{gathered}
Q=205 \times 120 \times 0.001 \\
\mathbf{Q}=\mathbf{2 4 . 6 \mathbf { W }}
\end{gathered}
$$

Convective heat transfer coefficient, $\mathbf{h}=\frac{\mathbf{Q}}{\mathbf{A}_{\mathbf{f}}} \quad($ From 2$)$ $\mathrm{Q}=24.6 \mathrm{~W}$

Convection Area, $\mathrm{A}_{\mathrm{f}}=\pi \mathrm{r}^{2}$

$A_{\mathrm{f}}=0.00172787 \mathrm{~m}^{2}$

$$
\mathrm{h}=\frac{24.6}{0.00172787}
$$

Thermal conductivity of NBR, $\mathrm{k}=0.24 \frac{\mathrm{W}}{\mathrm{mK}}$ 
International Journal of Science and Research (IJSR)

ISSN (Online): 2319-7064

Index Copernicus Value (2013): 6.14 | Impact Factor (2014): 5.611

$$
h=14237.1822 \frac{W}{m^{2}}
$$

The API default for 12S, $U=\sqrt{\left(\frac{h k}{L}\right)\left(\frac{t}{L}\right)}$

(From 3)

Thickness of aluminium, $\mathbf{t}=0.001 \mathrm{~m}$

Width of the oil seal, $\mathrm{L}=0.065 \mathrm{~m}$

$$
\begin{gathered}
U=\sqrt{\left(\frac{14237.182 * 205}{0.065}\right)\left(\frac{0.001}{0.065}\right)} \\
U=\sqrt{690798.6864} \\
\mathbf{U}=\mathbf{8 3 1 . 1 4 3}
\end{gathered}
$$

Heat Soak, $\mathbf{H}_{\mathbf{s}}=\mathbf{m}_{1} \mathbf{m}_{2} \mathbf{m}_{3} \mathbf{m}_{4} \mathbf{m}_{5} \mathbf{m}_{6} \mathbf{U} \mathbf{A}_{\mathbf{f}} \Delta \mathbf{T}$ (From 4)

Speed factor, $\mathrm{m}_{1}=1$ (Since the fluid is constant)

Thermal Conductivity factor, $\mathrm{m}_{2}=1$ (According to API 682)

Thickness factor, $\mathrm{m}_{3}=1.13$ (For 1.5 " grade seals, according to API 682)]

Bore factor, $\mathrm{m}_{4}=1$ (According to API 610 standard bore and seal size)

Viscosity factor, $\mathrm{m}_{5}=1$ (Base case, according to API 682)
Combined fluid properties factor, $\mathrm{m}_{6}=0.78$ (Synthetic oil barrier fluids)

$$
\begin{array}{r}
\mathrm{H}_{\mathrm{s}}=1 \times 1 \times 1.13 \times 1 \times 1 \times 0.78 \times 831.143 \\
\times 0.00172787 \times 120
\end{array}
$$

$$
H_{s}=151.894171 \mathrm{~J} / \mathrm{s}
$$

On comparing the results of $\mathbf{A} \& \mathbf{B}$, so we infer that the heat transfer capacity of the aluminium is pretty higher. In this case, the oil seal gets cooled in the short span of time. Considering the laws of thermodynamics the heat flow always occurs from higher temperatures to lower temperatures. So, the aluminium coating helps in further excitation for heat transfer to occur. Thus, resulting in the increase of durability.

\begin{tabular}{|c|c|c|c|c|c|c|c|c|}
\hline \multirow{2}{*}{ S. No } & \multirow{2}{*}{ Specimen } & \multirow{2}{*}{$\frac{\text { Test Solutio }}{\%}$} & & \multirow{2}{*}{ End Time } & \multirow{2}{*}{$\frac{\text { Final Weight }}{\sigma}$} & Area & \multirow{2}{*}{$\frac{\text { Time of Exposure }}{\text { minutes }}$} \\
\hline & & & \multicolumn{2}{|c|}{\begin{tabular}{|c|c|} 
Start Time & Initial Weight \\
hh:mm
\end{tabular}} & & & $\mathrm{cm}^{2}$ & \\
\hline 1 . & & $\begin{array}{c}5 \% \mathrm{NaCl} \text { with distilled } \\
\text { water }\left(\mathrm{H}_{2} \mathrm{O}\right)\end{array}$ & $\begin{array}{c}10: 20 \\
\mathrm{AM}\end{array}$ & 29.5385 & $\begin{array}{l}12: 20 \\
\mathrm{PM}\end{array}$ & 29.5359 & 1.6265 & \\
\hline
\end{tabular}

\subsection{Corrosion Test}

\subsubsection{Observation and Tabulation}

Thus the corrosion test for the specimen is observed and the values are being tabulated in the table 6 and the weight before and after test are shown in figure $19 \& 20$

Table 6: Observation during the experiment

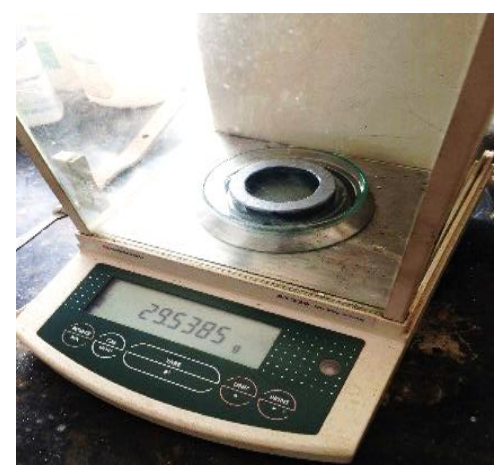

Figure 19: Weight before test

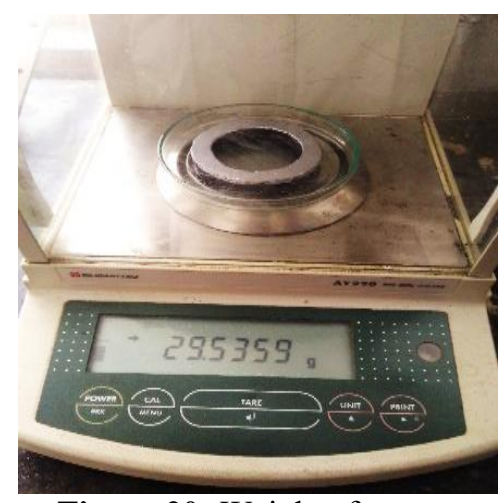

Figure 20: Weight after test

\subsubsection{Calculation}

The corrosion rate for the specimen is calculated by the equation (5) and the observed values are being tabulated in the table 6
Corrosion Rate, $C_{r}=\frac{534\left(w t_{i}-w t_{F}\right)}{A t d}$

(From 5)

$$
\begin{gathered}
C_{r}=\frac{534(29.5385-29.5359)}{1.6265 * 120 * 2.7} \\
C_{r}=\frac{534(0.0026)}{526.986} \\
C_{\boldsymbol{r}}=\mathbf{0 . 0 0 2 6 3}
\end{gathered}
$$

The corrosion rate is very minimal, thus having high resistance to corrosion, inferring coated oil seal is safe to be used in the earth movers conventionally.

\section{Conclusion}

Now when we have the data with us, we can compare these results of heat dissipation and fatigue life with the results we will get after the physical testing of the oil seal that we designed with the commercial oil seal with exact dimensions and geometry referring to the vehicle manual.

The demonstration of the project with two oil seals also served our purpose to emphasize the most important and useful advantage of the analysis that we can change our model to achieve the desirable results.

From the inference we conclude that the heat dissipation in the oil seal with coating is more than the oil seal without coating, but the results obtained inferred that there is a huge increase in heat dissipation that the oil seal gets cooled quickly that retains the weariness to some extent.

\section{Volume 5 Issue 2, February 2016}




\section{International Journal of Science and Research (IJSR) \\ ISSN (Online): 2319-7064}

Index Copernicus Value (2013): 6.14 | Impact Factor (2014): 5.611

The corrosion test indicated that the rate of corrosion of the aluminium coated oil seal is in the range of negligence. Thus the aluminium coated oil seal can be used conventionally, thus the aims of this thesis have been met. The simulations carried out revealed opportunities for significant improvements and these opportunities were carried through into design goals and implemented in the final design. It is hoped, with proper coating, that the final design will deliver a measureable gain in the durability of the oil seal. This thesis has provided some valuable knowledge in the enhancement in durability and application of oil seal in any environments.

\section{References}

[1] Nick Peppiatt (Hallite Seals International, UK) and Bob Flitney (BHR Group, UK), "International standards for reciprocating seals used in hydraulic applications", Sealing Technology July 2004.

[2] Shuai Li, WentieNiu, Hongtao Li, Shengli Fu, "Numerical analysis of leakage of elastomeric seals for reciprocating circular motion", Tribology International 83(2015)21-32.

[3] Michel Tourloniasa, Marie-Ange Bueno, RomainBocquet, René Rossi,SiegfriedDerle, "Study of the friction mechanisms of pile surfaces: Measurement conditions and pile surface properties", Wear 328329(2015)100-109.

[4] Dipl.-Ing. Dirk Weber and Prof. Dr.-Ing. habil. Werner Haas, "Wear behaviour of PTFE lip seals with different sealing edge designs, experiments and simulation, IMA Institute of Machine Components", University of Stuttgart, German, Sealing Technology February 2007.

[5] George K. Nikas, Richard S. Sayle, "Study of leakage and friction of flexible seals for steady motion via a numerical approximation method", Tribology International 39(2006)921-936.

[6] Lewis E. Shoemaker and James R. Crum, "NickelMolybdenum- Chromium Super alloys: The solution to corrosion problems in wet limestone FGD air pollution control systems", Special Metals Corporation, Huntington, WV USA.

[7] Thomas Papatheodorou- Parker Hannifin GmbH, "Influence of hard chrome plated rod surface treatments on sealing behaviour of hydraulic rod seals", Pradifa Packing division, Bietigheim- Bissingen, Germany, Sealing Technology April 2005.

[8] LotharHorl, Werner Haas and Ulrich Nibler, "A comparison of test methods for hydraulic rod seals IMA", University of Stuttgart, Germany, Sealing Technology, December 2009.

[9] TCR Engineering Services, "Corrosion Testing", A material Testing Laboratory, August 2008.

[10]GORDON S. BACK, "An improved heat soak calculation for mechanical seals", Field Operations, John Crane Inc., Proceedings of the Twenty Sixth International Pump Users Symposium, 2010.

[11]Bob Flitney, Editor, "Review of Sealing features", Sealing Technology, May 2005.

\section{Author Profile}

Mr. R. Vishnu Ramesh Kumar, Assistant Professor, Department of Automobile Engineering, Dr. Mahalingam College of Engineering and Technology, Pollachi- 642003, did his Bachelor's degree in Automobile Engineering and Master's degree in $\mathrm{CAD} / \mathrm{CAM}$.

V. Varun Sagar, Undergraduate Student, Department of Automobile Engineering, Dr. Mahalingam College of Engineering and Technology, Pollachi- 642003, is doing his Final year Bachelor's program in Automobile Engineering.

P. Vishnuram, Undergraduate Student, Department of Automobile Engineering, Dr. Mahalingam College of Engineering and Technology, Pollachi- 642003, is doing his Final year Bachelor's program in Automobile Engineering.

N. Hari Prasanth, Undergraduate Student, Department of Automobile Engineering, Dr. Mahalingam College of Engineering and Technology, Pollachi- 642003, is doing his Final year Bachelor's program in Automobile Engineering. 